\title{
BMJ Open Work-based risk factors and quality of life in health care workers providing maternal and newborn care during the Sierra Leone Ebola epidemic: findings using the WHOQOL-BREF and HSE Management Standards Tool
}

Susan Jones (1) , ${ }^{1}$ Sarah White (1) , ${ }^{2}$ Judith Ormrod, ${ }^{3}$ Betty Sam, ${ }^{2}$ Florence Bull, ${ }^{2}$ Steven Pieh, ${ }^{2}$ Somasundari Gopalakrishnan, ${ }^{2}$ Nynke van den Broek ${ }^{2}$

To cite: Jones S, White S, Ormrod J, et al. Work-based risk factors and quality of life in health care workers providing maternal and newborn care during the Sierra Leone Ebola epidemic: findings using the WHOQOLBREF and HSE Management Standards Tool. BMJ Open 2020;10:e032929. doi:10.1136/ bmjopen-2019-032929

- Prepublication history for this paper is available online. To view these files, please visit the journal online (http://dx.doi. org/10.1136/bmjopen-2019032929).

Received 12 July 2019 Revised 11 August 2020 Accepted 24 August 2020

D Check for updates

(c) Author(s) (or their employer(s)) 2020. Re-use permitted under CC BY-NC. No commercial re-use. See rights and permissions. Published by BMJ.

For numbered affiliations see end of article.

Correspondence to

Susan Jones;

S.Jones@hud.ac.uk

\section{ABSTRACT}

Introduction Before the 2014, Ebola epidemic in Sierra Leone, healthcare workers (HCWs) faced many challenges. Workload and personal risk of HCWs increased but their experiences of these have not been well explored. HCWs evaluation of their quality of life (QoL) and risk factors for developing workbased stress is important in helping to develop a strong and committed workforce in a resilient health system.

Methods Cross-sectional study using World Health Organisation Quality of Life (WHOQOL)-BREF and Health and Safety Executive (HSE) Standards Tools in 13 Emergency Obstetric Care facilities to (1) understand the perceptions of HCWs regarding workplace risk factors for developing stress, (2) evaluate HCWs perceptions of QoL and links to risk factors for workplace stress and (3) assess changes in QoL and risk factors for stress after a stress management programme. Results 222 completed the survey at baseline and 156 at follow-up. At baseline, QoL of HCWs was below international standards in all domains. There was a significant decrease in score for physical health and psychological well-being (mean decrease $(95 \% \mathrm{Cl}) ; 2.3(0.5-4.1)$ and $2.3(0.4-4.1))$. Lower cadres had significant decreases in scores for physical health and social relationships (13.0 (3.6-22.4) and 14.4 (2.6-26.2)). On HSE peer-support and role understanding scored highly (mean scores 4.0 and 3.7 on HSE), workplace demands were average or high-risk factors (mean score 3.0). There was a significant score reduction in the domains relationships and understanding of role (mean score reduction $(95 \% \mathrm{Cl}) 0.16$ $(0.01-0.31)$ and $0.11(0.01-0.21))$, particularly among lower cadres $(0.83(0.3-1.4)$.

Conclusion HCWs in low-resourced settings may have increased risk factors for developing workplace stress with low QoL indicators; further exploration of this is needed to support staff and develop their contribution to the development of resilient health systems.

\section{INTRODUCTION}

Prior to the Ebola virus disease (EVD) epidemic, Sierra Leone already faced many challenges in providing healthcare due to a lack of resources and a shortage of qualified
Strength and limitations of this study

- This is the first study to explore the problem of work-based stress and quality of life among healthcare providers providing emergency obstetric care in Sierra Leone.

- Using both the HSE questionnaire and the WHOQOLBREF allowed the assessment of workplace risk factors for stress on workers demonstrating high levels of stress, limited support and overall low quality of life. Findings from the study were used by the Ministry of Health and Sanitation and included in an induction programme for healthcare workers on managing work-based stress.

- The timing between baseline and follow-up was only 8 weeks and it would have been useful to extend the study to assess the effectiveness of the programme for at least 6 months.

- The study was completed during the Ebola epidemic, which may have altered stress levels of healthcare workers compared with the period prior to the epidemic. No studies are available on the levels of stress among healthcare workers prior to the epidemic.

- We did not assess any changes within the working environment from baseline to follow-up as the Ebola epidemic progressed or take account of external factors, and this may have impacted the final results. The authors acknowledge that when using multiple tests of statistical significance there is an increased risk of spurious statistically significant findings.

healthcare workers (HCWs), with just 0.22 nurses/midwives and 1.66 medical doctors per 10000 population compared with the WHO recommendation of 23 doctors and nurses/midwives per 10000 population. ${ }^{1}$ The lack of adequately trained professionals means that both nurses and doctors 
frequently find themselves working in isolation, with minimal peer support yet required to provide care to both chronically and acutely ill patients. In addition to the low numbers of nurses and doctors, there is also a lack of senior staff with post basic, specialist training and experience, resulting in junior or inexperienced staff taking on additional clinical skills that they may not be trained for. ${ }^{2}$ Working conditions for all cadres of staff in all grades of facilities, from primary to tertiary care, are poor, without a regular supply of electricity and/ or running water and a chronic shortage of medicines and clinical supplies. As a consequence of this, staff are unable to provide the optimum, and sometimes even the most basic, level of patient care.

The scale of the 2014-2015 EVD epidemic across West Africa was unprecedented with a total of 27049 cases and 11149 deaths across the three countries worst affected (Sierra Leone, Guinea and Liberia). ${ }^{3}$ Sierra Leone reported 8704 confirmed cases and 3589 deaths. HCWs in Sierra Leone were severely affected with a $74 \%$ case fatality rate among HCWs who contracted EVD (296 cases, 221 deaths) compared with an overall case fatality rate of $41 \%$ in the general population.

The continuing fragile state of the Sierra Leone health system following the end of the civil war meant that the country was ill prepared to manage such a large-scale health emergency. ${ }^{4}$ During the epidemic, HCWs experienced several additional challenges to those faced in their normal working life. These included an increased risk to their own health, concerns for the safety of their families and community, loss of colleagues and a further increased workload. ${ }^{5}$ All of these are likely to have contributed to increasing levels of workplace stress. When caring for highly infectious Ebola patients, there is evidence to show that staff are able to cope better if there are adequate resources and training. ${ }^{67}$ However, in a low-resourced setting, adequate levels of training and resources may not be available.

Stress has been defined as a state in which individuals are unable to bridge the gap between what is expected and required of them and what they can achieve. ${ }^{8}$ However, prolonged stress can lead to reduced effectiveness at work and even cause ill health. ${ }^{8}$ The Job-Demand Resources (JD-R) model describes work-related stress as being the result of the inability to meet demands placed on an individual within the context of their work role. ${ }^{910}$ Demands such as the overall workload and the time set for completing this combined with the degree of control over the working day are determinants of job-related anxiety, psychological strain, ill health and burnout. ${ }^{9} 10$ In the JD-R model, 'demands' encompass all those physical and/or psychological aspects of the job that require effort on the part of the worker. Alternative theories of workplace stress consider the "effort and reward imbalance' (ERI) rather than the demands and control. ${ }^{8}$ The ERI model assumes that where there is an imbalance between effort (work demands and intrinsic motivation) and reward (salary, job security, career opportunities), then job strain will occur. This strain can then lead to ill health and burnout. ${ }^{11}$

Finding ways to help workers better cope with stressful environments has led some researchers to look at the role of resilience within the workplace. Resilience has been defined as 'the ability to adapt to adversity', ${ }^{12}$ or the 'ability to rebound or 'bounce back' from adversity'. ${ }^{13}$ Early work on resilience focused on individual resilience (especially with regard to vulnerable children), community and family resilience. More recent research has considered how both employees and organisations themselves can impact resilience. Resilience is seen as a positive organisational factor that can help individuals and organisations (especially healthcare organisations) reduce absenteeism, improve the well-being of HCWs and patient care. ${ }^{14}$ Predictors of resilience include adaptability, psychological attributes, finding meaning in adversity, having a positive identity, positive coping skills, social support and spiritual connection. ${ }^{15}$ A lack of resilience in the workplace and increased work-based stress levels may also impact the overall quality of life (QoL) negatively impacting not just on the individual but the wider family group and community. ${ }^{15}$

The above-mentioned concepts of work-related stress among HCWs are a well-recognised phenomenon in highincome settings and it is known that midwives, nurses and doctors have specific operational pressures that are exacerbated by the dynamic working environment of healthcare provision. ${ }^{11}$ Issues such as workload, job satisfaction and engagement with work have been shown to impact nurse's psychological health, demonstrating that both personal and workplace factors can influence stress levels. $^{16}$

Increased levels of stress can lead to poor performance at work and in healthcare, this may affect patient outcomes. ${ }^{91517}$ However, there is little information available from low-imcome and middle-income countries regarding the understanding, experiences and,effect of stress on job satisfaction and the ability of HCWs to fulfil their roles or not. ${ }^{18}$ What evidence there is from low-income and middle-income countries shows that, rather than concentrating on the numbers of available HCWs, there needs to be a focus on the work climate and job satisfaction to help develop productive workers and reduce risk factors for stress. ${ }^{19}$ Providing interventions to limit workplace risk factors for stress may help to prevent burnout among workers, which can lead to emotional exhaustion, disconnect from the workplace, a lack of personal accomplishment and lead to poor patient care ${ }^{20}$

In the context of the EVD outbreak in Sierra Leone, there were new and additional expectations placed on HCWs. HCWs were expected to manage patients with a disease that was previously unknown within the country while continuing work in an environment with inadequate resources to do this safely. ${ }^{21}$ The risk of infection for HCWs in maternity care areas was further exacerbated because of the frequent risk of contact with bodily fluids when caring for women during the various stages 
of pregnancy and particularly during birth. ${ }^{18}$ In addition, it is known that the signs and symptoms of obstetric emergencies such as haemorrhage or sepsis mirror those of EVD and this can make it difficult to differentiate between women who require emergency obstetric care in a standard maternity care setting and women who have signs and symptoms of EVD and require management in separate specialised areas. ${ }^{18}$

This study aimed to (1) understand the perceptions of healthcare providers regarding workplace risk factors for developing stress, (2) evaluate HCW's perceptions of QoL and its links to risk factors for developing workplace stress and (3) assess changes in QoL and risk factors for stress after a stress management programme.

\section{METHODS}

Given the country-specific context at the time of the study (the ongoing Ebola epidemic) and the continued low-resourced and fragile state of the healthcare system in Sierra Leone, we used the JD-R model as the conceptual framework for this study. The study took place from January to September 2015 with data collection and the stress management programme occurring between the months of July and August 2015 when the number of Ebola cases was reducing rapidly; Sierra Leone was declared free of Ebola in November 2015. ${ }^{18}$

\section{Participants}

A purposive sample of 3 (Freetown Rural, Freetown Urban and Bo) out of a total of 14 districts in Sierra Leone were chosen at the request of the Ministry of Health and Sanitation (MoHS). All 13 healthcare facilities designated as providing either Basic Emergency Obstetric Care (BEmOC) or Comprehensive Emergency Obstetric Care $(\mathrm{CEmOC})^{18}$ within the selected districts were included. All staff in each health facility $(n=222)$ were invited to participate in the study. Given the time scale of the study, it was not possible to conduct a pilot study.

\section{Patient and public involvement}

No patients or members of the public were included in the study.

\section{Consent to participate}

Participants were provided with both verbal and written explanations of the study and asked to sign an informed consent if they wished to take part. Participation in completing the questionnaire was voluntary and participants could opt out at any stage.

\section{Data collection and tools}

Two self-administered questionnaires (HSE Standards tool and World Health Organisation Quality of Life (WHOQOL)-BREF) were completed by participants at baseline and again 8 weeks after a training workshop in stress management. The questionnaires were in English which is widely spoken in Sierra Leone and the de facto official language. All primary, secondary and tertiary education and HCW training are conducted in English. No validated tools were available that had been used to look at work-related stress within Sierra Leone, which reflects the lack of research in this area.

The UK Health and Safety Executive (HSE) Management Standards Tool for work-related stress was used to measure HCW's perceptions of workplace risk factors that may increase workers' stress as it has been used across a number of countries and for a wide variety of workers. ${ }^{22}$ The questionnaire includes six main areas that can potentially influence a HCW' environment: (1) the workload demands on workers; (2) the control workers feel they have in organising and managing their workload; (3) the support through encouragement, sponsorship and resources that workers feel that they receive from their managers and peers; (4) the presence of healthy workplace relationships to promote positive working and prevent conflict; (5) whether people understand their role in the organisation and (6) how organisational change is managed and communicated in the organisation..$^{20}$ For purposes of analysis and to provide more detail, domain 3 (peer and manager support) is separated giving a total of seven domains. Scoring is via a Likert scale from 1 to 5. A score of 3 is average. A score of 1-2 is indicative of extreme stress. A score of 4-5 is indicative of low stress levels. The HSE provides a data analysis tool and recommendations on the smallest sample size to be included from the workplace. Where there are fewer than 500 workers, it is recommended that all workers are given the opportunity to participate.

Stress in the workplace may also have an impact on home and social life. Therefore, HCWs' assessment of their QoL were measured using the WHOQOL-BREF ${ }^{23}$ questionnaire, which is based on the WHOQOL-100 and was developed to provide a shorter form for QoL assessment. The WHOQOL-BREF includes 26 of the 100 questions in the WHOQOL-100 and includes the same four domains contributing to QoL, (1) physical health (7 questions, eg, activities of living, energy, fatigue),(2) psychological health (6 questions, eg, body image, negative feelings, self-esteem), (3) social relationships (3 questions, eg, personal relationships, social support) and (4) the environment (8 questions, eg, finance, home environment, freedom, transport) ${ }^{23}$ Scoring for each question is on a Likert scale from 1 to 5 . For each domain, raw scores were averaged and converted to percentage scores as per WHO syntax for the WHOQOL-BREF, with higher scores reflecting the higher QoL. The validated questionnaire has been used widely across a variety of populations and in high-income, low-income and middle-income countries.

\section{Programme for recognition and management of workplace- related stress}

A total of 52, facility-based, lead HCWs (a subset of the 222 participants) (4 from each of the 13 healthcare facilities) participated in a 1-day stress management programme and in the completion of the questionnaires with the remaining facility staff (total 222). The programme 
aimed to (1) provide basic training for key HCWs in stress management who could then go on to provide support in stress management to staff in their workplace; (2) provide participants with the basic skills to recognise risk factors for workers developing stress in their workplace. Participants for the programme were selected in cooperation with the facility teams and the District Health Management teams based on their role in the facility and the level of managerial support they were expected to give. Health facility managers were included in the training as they are often part of the support network for staff in Sierra Leone. The programme helped HCWs to recognise and manage stress and develop resilience in the workplace. Participatory, student-focused teaching techniques (eg, group work, role play, individual work) were used to encourage participant interaction and engagement, help to develop problem-solving skills and facilitate learning. ${ }^{24}$ Short lectures and question and answer sessions were also used to deliver some theoretical aspects of the course. The sessions included learning on: (1) the physical, emotional, behavioural and psychological manifestations of stress in a HCW; (2) the concept of resilience and recognising this as a mixture of personal characteristics and skills that can be developed through training; (3) recognising signature strengths, coping with challenging thoughts and using 'tough' experiences; (4) recognising what makes one feel good including physical, spiritual and social support factors and managing stress through relaxation, coping mechanisms and mindfulness. On return to their workplace, participants were expected to be better able to recognise risk factors for workplace stress in their areas, provide colleagues with training in the recognition and management of workplace stress, and develop strategies to manage risk factors in their work area. Between baseline and follow-up, researchers from the Liverpool School of Tropical Medicine (LSTM) continued to liaise with the relevant healthcare facilities to offer support and monitor the use of the workshop. LSTM researchers were also asked by the MoHS to provide similar but shorter training sessions for newly appointed HCWs in the year following the initial workshop.

Before implementation, the content of the programme was reviewed in consultation with local healthcare providers to ensure that all aspects were locally relevant. All training was facilitated in-country jointly by national and international facilitators using a participatory adult learning approach that included group work, discussion and self-led participant exercises.

\section{Data analysis}

For the HSE questionnaire, descriptive analysis was used to provide information on each of the seven competency areas: demands, control, support (managers and peer), relationships, role and organisational change. Scores for each area and overall were calculated for both baseline (before the training programme) and follow-up. Baseline scores for each area and overall were analysed using a three-way analysis of variance with factors for the district, cadre (five categories excluding 1 doctor and four managers) and facility type to identify any pre-existing statistically significant differences between categories for these factors. Follow-up scores were compared with baseline scores for each area and overall were compared using paired t-tests. To examine whether the cadre of staff, the district or the facility type influenced any change in scores analysis of covariance (ANCOVA) was used. The scores after training as were used for the response scores at baseline as covariates (to estimate the contribution of the baseline score to the follow-up score) and factors for each of cadre, district and facility type (to estimate any differences after accounting for baseline differences). Estimated differences are reported with 95\% CIs.

Scores for each domain of the WHOQOL-BREF and overall were derived following the syntax provided by WHO (http://www.who.int/mental_health/media/en/ 76.pdf). The mean score for each question within each domain was used to calculate the overall domain score. Mean scores were multiplied by 4 to make them comparable with the scores used in the WHOQOL-100. Where $20 \%$ of data was missing from the WHOQOL-BREF questions, the data for that domain for the respondent were discarded. Otherwise, where an item was missing the mean of the other items was substituted. Population norms for the four domains were calculated in a study by Hawthorne $e t$ al using randomly sampled communities from Victoria, Australia in two studies. ${ }^{25}$ These were used as the international standard for comparison in this study. The values are provided by domain: Physical health 73.5 (SD=18.1); Psychological well-being 70.6 (14.0); Social relationships 71.5 (SD 18.2) and Environment 75.1 (SD 13.0).

\section{RESULTS}

All 222 workers in the facilities agreed to participate in the study. Of the 222 workers assessed at baseline 156 were reassessed. At baseline, 222 participants completed the HSE questionnaire and the WHOQOL-BREF. Of these, 156 completed at least one of the questionnaires at follow-up (2 participants only completed one but not the other of the two questionnaires). The majority of respondents were female individuals $(199 / 222,89.6 \%)$ and aged between 25 and 45 years $(163 / 222,73.4 \%)$ (table 1$)$.

At baseline, mean scores from the HSE questionnaire indicated an average risk of developing stress (a score of 3 ) in four of the seven domains (control over work, relationships, managers support and response to workplace change). Scores for two of the domains (peer support and understanding of role) were indicated as low-risk factors for developing stress (between 1 and 2). The highest risk factor for developing workplace stress at baseline was in the domain of workplace demands. When all domains were combined, there was an average risk for developing workplace stress.

WHOQOL-BREF results at baseline demonstrated a self-reported, low QoL across all domains (physical 
Table 1 Characteristics of respondents assessed at baseline and at follow-up

\begin{tabular}{|c|c|c|}
\hline Category & $\begin{array}{l}\text { Number } \\
\text { assessed at } \\
\text { baseline } \\
(\mathrm{N}=222), \mathrm{n}(\%)\end{array}$ & $\begin{array}{l}\text { Number } \\
\text { assessed at } \\
\text { follow-up } \\
(\mathrm{N}=156), \mathrm{n}(\%)\end{array}$ \\
\hline \multicolumn{3}{|l|}{ District } \\
\hline Urban Freetown & 85 (38.3) & $51(32.7)$ \\
\hline Rural Freetown & $49(22.1)$ & $35(22.4)$ \\
\hline Bo & $83(37.4)$ & $66(42.3)$ \\
\hline \multicolumn{3}{|l|}{ Cadre } \\
\hline Doctor & $1(0.4)$ & $1(0.6)$ \\
\hline Registered nurse-midwife & $21(9.5)$ & $17(10.9)$ \\
\hline Middle-grade staff & $19(8.6)$ & $14(9.0)$ \\
\hline $\begin{array}{l}\text { Maternal and Child Health } \\
\text { Aide or State Enrolled } \\
\text { Community Health Nurse }\end{array}$ & $138(62.2)$ & $94(60.3)$ \\
\hline Care assistant & $31(14.0)$ & $23(14.7)$ \\
\hline Support staff & 7 (3.2) & $6(3.9)$ \\
\hline Manager & $4(1.8)$ & $1(0.6)$ \\
\hline \multicolumn{3}{|l|}{ Facility type } \\
\hline Comprehensive EmOC & $76(34.2)$ & $46(29.5)$ \\
\hline Basic EmOC & $146(65.8)$ & $110(70.5)$ \\
\hline \multicolumn{3}{|l|}{ Gender } \\
\hline Male & $20(9.0)$ & $16(10.3)$ \\
\hline Female & $199(89.6)$ & $137(87.8)$ \\
\hline
\end{tabular}

EmOC, emergency obstetric care.

health, psychological well-being, social relationships and environment) compared with population norms. When combined with results of the HSE questionnaire, this raises concerns about the ability of HCWs to cope in their workplace, particularly given the high workplace demands that they face. Detailed results of the HSE and WHOQOL-BREF are given ahead.

Participants were inclusive of all maternity staff cadres; $62.2 \%(138 / 222)$ of respondents were Maternal and Child Health Aides (MCHA) and State Enrolled Community Health Nurses (SECHN) who together make up the majority of HCWs in Sierra Leone. Other cadres included Registered Nurse-Midwives (21/222; 9.5\%) and MiddleGrade staff $(19 / 222 ; 8.6 \%)$. In addition, care assistants $(31 / 222 ; 14.0 \%)$ and support staff $(7 / 222 ; 3.2 \%)$ were included in the assessment. For the purposes of further assessment, nurse midwives, MCHA, SECHN and middlegrade staff or doctors were considered to have a 'higher level' of training and care assistants and support staff were considered to have a 'lower level' of training.

\section{Workplace risk factors (HSE questionnaire)}

The lowest scores (highest risk) both at baseline and at follow-up were obtained for the domain workplace demands. At baseline, this had a mean (SD) value of 2.98
(0.56) (table 2) which did not vary significantly between districts, cadres or facility type. At follow-up, the mean (95\% CI) change from baseline was 0.02 ( -0.09 to 0.13 ) (table 2).

When baseline scores for all domains were combined for all participants, the mean score across all HSE domains combined (3.74) is indicative of average risk for HCWs developing stress.

For each domain, Cronbach's $\alpha$ at baseline was between 0.51 and 0.65 , which is too low to indicate satisfactory consistency (table 1). For those assessed at follow-up, Cronbach's $\alpha$ for the overall score was 0.75 , which indicates satisfactory consistency, whereas for each domain, the values were between 0.46 and 0.69 , which do not indicate satisfactory consistency (table 2 ).

The mean $(95 \% \mathrm{CI})$ reductions in the score were 0.21 $(0.14-0.28)$ for the overall score, $0.16(0.01-0.31)$ for relationships and $0.11(0.01-0.21)$ for the understanding of the role (table 2) indicating that the risk in these areas increased during the pandemic. ANCOVA (the coefficient derived in the ANCOVA for the contribution of the baseline stress score for the domain under analysis) estimated the coefficient for the contribution of the baseline stress score to the follow-up score to vary between 0.16 (response to workplace change) and 0.46 (for control over work environment) and 0.48 (for HSE domains combined). ANCOVA found evidence of a difference between cadres in follow-up scores, after accounting for baseline scores, for relationships (lower qualified staff were estimated to score 0.83 lower than higher qualified staff) and understanding of the role (lower qualified were estimated to score 0.36 lower than higher qualified staff). For the understanding of the role, there was also evidence of a difference between districts (those in Bo were estimated to score 0.26 lower than those in Urban Freetown; table 3).

\section{WHOQOL-BREF questionnaire}

For the WHOQOL-BREF scores, Cronbach's $\alpha$ at baseline was 0.83 , which indicates very satisfactory consistency for the overall score. For the environment domain, it was also satisfactory, with a value of 0.71 . However, for the other three domains, Cronbach's $\alpha$ at baseline was between 0.57 and 0.65 , which is too low to indicate satisfactory consistency (table 4). For those assessed at follow-up, consistency was similarly very satisfactory for WHOQOLBREF (Cronbach's $\alpha$ : 0.84), satisfactory for environment (0.76) and not satisfactory for the other domains (Cronbach's $\alpha$ between 0.64 and 0.67 ; table 4 ).

The mean scores for each of the domains for all participants combined were below the international average for each of the domains of the WHOQOL-BREF questionnaire at both baseline and follow-up (table 4). At baseline, the mean (95\% CI) score for Bo was 4.6\% (1.7\%-7.5\%) (lower than for Freetown Urban) and differed between facility type indicating a lower QoL for those workingoutside of the capital (Freetown). The mean scores for healthcare facilities designated to provide CEmOC were lower (that is HCWs 
Table 2 Comparisons of scores at baseline and follow-up for workplace risk factors by domain (HSE questionnaire) ${ }^{\star}$

\begin{tabular}{|c|c|c|c|c|c|c|c|}
\hline \multirow[b]{2}{*}{ Domain } & \multicolumn{3}{|l|}{ Baseline } & \multicolumn{3}{|c|}{ Follow-up } & \multirow{2}{*}{$\begin{array}{l}\begin{array}{l}\text { Change from } \\
\text { baseline to follow-up }\end{array} \\
\begin{array}{l}\text { Mean } \\
(95 \% \mathrm{Cl})\end{array}\end{array}$} \\
\hline & $\mathrm{n} / \mathrm{N} \boldsymbol{1}$ & Cronbach's $\alpha$ & $\begin{array}{l}\text { Mean } \\
\text { (SD) }\end{array}$ & $\mathbf{n} \ddagger$ & Cronbach's $\alpha$ & $\begin{array}{l}\text { Mean } \\
\text { (SD) }\end{array}$ & \\
\hline Workplace demands & $213 / 220$ & 0.55 & $\begin{array}{l}2.98 \\
(0.56)\end{array}$ & 139 & 0.64 & $\begin{array}{l}2.98 \\
(0.59)\end{array}$ & $\begin{array}{l}0.02 \\
(-0.09 \text { to } 0.13)\end{array}$ \\
\hline Control over work environment & $213 / 220$ & 0.64 & $\begin{array}{l}3.22 \\
(0.70)\end{array}$ & 145 & 0.69 & $\begin{array}{l}3.19 \\
(0.71)\end{array}$ & $\begin{array}{l}-0.08 \\
(-0.19 \text { to } 0.04)\end{array}$ \\
\hline Managers' support & $213 / 220$ & 0.56 & $\begin{array}{l}3.80 \\
(0.66)\end{array}$ & 150 & 0.50 & $\begin{array}{l}3.77 \\
(0.59)\end{array}$ & $\begin{array}{l}-0.08 \\
(-0.20 \text { to } 0.04)\end{array}$ \\
\hline Peer support & $213 / 220$ & 0.51 & $\begin{array}{l}4.08 \\
(0.56)\end{array}$ & 150 & 0.58 & $\begin{array}{l}4.05 \\
(0.58)\end{array}$ & $\begin{array}{l}-0.09 \\
(-0.19 \text { to } 0.00)\end{array}$ \\
\hline Relationships & $213 / 220$ & 0.54 & $\begin{array}{l}3.67 \\
(0.74)\end{array}$ & 147 & 0.69 & $\begin{array}{l}3.55 \\
(0.85)\end{array}$ & $\begin{array}{l}-0.16 \\
(-0.31 \text { to to } 0.01)\end{array}$ \\
\hline HSE domains combined & $209 / 216$ & 0.70 & $\begin{array}{l}3.74 \\
(0.36)\end{array}$ & 106 & 0.75 & $\begin{array}{l}3.58 \\
(0.35)\end{array}$ & $\begin{array}{l}-0.21 \\
(-0.28 \text { to to } 0.14)\end{array}$ \\
\hline
\end{tabular}

${ }^{*} \mathrm{~A}$ score of 3 is indicative of average levels of risk for stress, 4-5 indicates low levels and 1-2 high levels of risk for stress.

†Numbers given are those with data for domain and the three factors/number with data for domain

$\ddagger$ Numbers with data at baseline and follow-up for the domain.

HSE, Health and Safety Executive.

reported a lower QoL in these domains) than in BEmOC healthcare facilities for physical health $(6.4 \% \quad(3.4 \%-$ $9.5 \%))$, environment $(6.9 \%(3.5 \%-10.4 \%))$ and the overall combined score $(4.7 \%(2.1 \%-7.2 \%))$.

Between baseline and follow-up, there was a reduction in WHOQOL-BREF score for physical health $(95 \% \mathrm{CI})$ reduction: $2.3(0.5-4.1)$, for psychological well-being (mean $(95 \% \mathrm{CI})$ reduction: $2.3(0.4-4.1)$ and for the overall combined score (mean $(95 \% \mathrm{CI})$ reduction: 1.6 (0.2-3.0)), indicating a deterioration in QoL related to these domains. Analysis of covariance (ANCOVA) (the coefficient derived in the ANCOVA for the contribution of the baseline WHOQOL-BREF score for the domain under analysis) estimated the coefficient for the contribution of the baseline WHOQOL-BREF score to the follow-up score to vary between 0.29 for psychological well-being and 0.64 for environment. ANCOVA found no statistically significant evidence of differences between districts or facility type in the WHOQOL-BREF scores at follow-up. For cadre, the only differences found were for support staff for whom there was a lower mean $(95 \% \mathrm{CI})$ score than for registered nurse/ midwives in physical health (13.0 (3.6-22.4)), social relationships (14.4 (2.6-26.2) and the overall WHOQOL-BREF score (9.92 (1.9-17.9)) (table 5).

\section{DISCUSSION}

This study found that whereas the overall risk of stress was noted to be 'average', the level of risk for the development of stress was particularly related to the workplace demands placed on healthcare providers. This finding resonates with the JD-R model that sees the development of stress as an imbalance between the demands placed on workers and their ability to meet them. Control over the working environment is also a key component of the JD-R model, and though workers reported an average score for the risk factor related to control of their working environment, high job demands may increase this risk factor over time.

HCWs reported a good level of peer support that is in place with respondents having a good understanding of their roles. Both peer support and understanding of role can help to mitigate against developing workplace stress. Healthcare providers with a lower level of training and/ or working in a healthcare facility designated to provide CEmOC had more identified work-related stress risk factors than those who were more senior and/or working at a healthcare facility providing BEmOC. This has implications for the support and training these workers may need to cope with the demands of their job within this setting. With the correct training, equipment and support HCW from any cadre and in any setting should be able to cope with the demands placed on them, even during a crisis such as the Ebola epidemic.

The overall aim of the study was to help staff understand and recognise the risk factors for workplace stress and to begin to develop skills to better manage these risks. In the short term, the scores for workplace stress decreased further suggesting that HCWs might have 





Table 4 Comparison of scores at baseline and follow-up for workplace risk factors by domain (WHOQOL-BREF questionnaire)

\begin{tabular}{|c|c|c|c|c|c|c|c|c|}
\hline \multirow[b]{2}{*}{ Domain } & \multirow[b]{2}{*}{$\begin{array}{l}\text { International } \\
\text { standard (SD) }\end{array}$} & \multicolumn{3}{|l|}{ Baseline } & \multicolumn{3}{|c|}{ Follow-up } & \multirow{2}{*}{$\begin{array}{l}\text { Change from } \\
\text { baseline to follow-up } \\
\text { Mean } \\
(95 \% \mathrm{Cl})\end{array}$} \\
\hline & & $n^{*}$ & Cronbach's $\alpha$ & $\begin{array}{l}\text { Mean } \\
\text { (SD) }\end{array}$ & $\mathbf{N}$ & Cronbach's $\alpha$ & $\begin{array}{l}\text { Mean } \\
\text { (SD) }\end{array}$ & \\
\hline Physical health & $73.5(18.1)$ & $208 / 217$ & 0.57 & $\begin{array}{l}52.3 \\
(10.6)\end{array}$ & 150 & 0.64 & $\begin{array}{l}50.0 \\
(10.9)\end{array}$ & $\begin{array}{l}-2.3 \\
(-4.1 \text { to to } 0.5)\end{array}$ \\
\hline $\begin{array}{l}\text { Psychological well- } \\
\text { being }\end{array}$ & $70.6(14.0)$ & $212 / 221$ & 0.65 & $\begin{array}{l}54.3 \\
(9.4)\end{array}$ & 152 & 0.67 & $\begin{array}{l}52.2 \\
(10.2)\end{array}$ & $\begin{array}{l}-2.3 \\
(-4.1 \text { to to } 0.4)\end{array}$ \\
\hline Environment & $75.1(13.0)$ & $213 / 222$ & 0.71 & $\begin{array}{l}42.4 \\
(11.3)\end{array}$ & 153 & 0.76 & $\begin{array}{l}41.8 \\
(11.5)\end{array}$ & $\begin{array}{l}-0.7 \\
(-2.2 \text { to } 0.9)\end{array}$ \\
\hline WHOQOL-BREF & & $207 / 216$ & 0.83 & $\begin{array}{l}50.1 \\
(8.4)\end{array}$ & 148 & 0.87 & $\begin{array}{l}48.6 \\
(9.2)\end{array}$ & $\begin{array}{l}-1.6 \\
(-3.0 \text { to to } 0.2)\end{array}$ \\
\hline
\end{tabular}

*Numbers given are those with data for domain and the three factors/number with data for domain: population norms: physical health 73.5 (SD = 18.1); psychological well-being 70.6 (14.0); social relationships 71.5 (SD 18.2) and environment 75.1 (SD 13.0).

WHOQOL, World Health Organisation Quality of Life.

used a better knowledge and understanding of stress and workplace stress to reassess their working environment in more detail. To build resilience and to improve the workplace environment, more support is needed.

\section{Interpretation and implications for practice}

Below average scores in the WHOQOL-BREF questionnaire domains of physical and psychological health may be indicative of the negative effect workplace demands have on the physical and psychological well-being of healthcare providers. ${ }^{26}$ However, they may also be influenced by factors external to the work environment for workers living in a low-income country such as Sierra Leone. Previous studies have shown that workers who have high demands placed on them can show unsafe practices, which should be of particular concern in healthcare. ${ }^{27}$ In addition to workplace demands, previous studies have suggested that work-based and social support are also positively associated with well-being, lower levels of depression, burnout and psychological distress and greater life satisfaction. ${ }^{28} 29$ Health service managers therefore need to understand the impact of increased work load and support not just on the individual but also on quality of care and implement measures that support HCWs to maintain standards of care. These measures should include addressing the quality of preservice and in-service training, peer and managerial support and providing an enabling working environment.

Having an enabling environment (including adequate resources to work with) has also been shown to be an important factor in managing workplace demands in healthcare. ${ }^{30}{ }^{31}$ Prior to the EVD epidemic, HCWs in Sierra Leone were already working with too few resources within a weak health system. ${ }^{32}$ The need for additional equipment to safely manage patients with EVD exacerbated this lack of resources. Scores obtained in this study for environmental demand suggest this might be the case, and, these did not change in the short time, despite the influx of resources and money into Sierra Leone as part of the Ebola response effort. Healthcare providers in Sierra Leone face daily, long-term challenges both at home and in work with limited electricity and clean water supply, poor transport infrastructure and low standards of healthcare, which may all make managing workplace demands more challenging. Workers in the second city of the country, Bo, reported worse QoL than their peers in the capital Freetown. This may be due to the extra resources and facilities that are available within the capital city compared with Bo. In contrast, workers in Bo scored higher regarding workplace risk factors (that is there was less risk) compared with their peers in Freetown. The reasons for this are unclear and may relate to the types and number of patients seen in facilities, proximity or not to the MoHS, staffing levels and mix of cadres or other characteristics of the workplace.

Though designed for use in the UK, the HSE Management Standards Tool has also been used in a number of countries including Italy, the Philippines and Australia. ${ }^{33-35}$ An important element of this study was the development and use of culturally appropriate tools not only to measure and support work stressors and QoL but also to inform and allay fears within a culture where fear and stigma of psychological ill health is apparent. Finding an appropriate tool to measure resilience was difficult primarily due to the fact that many of the available measures may not be culturally sensitive and appropriate to the clinical setting and healthcare professionals. ${ }^{36}$ Because the HSE and WHOQOL-BREF had been used extensively in several other countries, and following negotiations with colleagues in Sierra Leone, it was considered appropriate to use these.

Within the context of this EVD epidemic, there may have been a need for additional support for HCWs to 
cope with the humanitarian situation. Previous studies suggest that the majority of healthcare workers exposed to traumatic or challenging events do not suffer from any long-term negative psychological effects and do display resilience, but the minority who do experience distress need to be supported. ${ }^{37}$ The EVD epidemic was associated with increased risk for healthcare providers who, however, largely remained in post to provide maternity care. Health managers need to better understand why it is that HCWs continued to provide care, despite the negative impact on themselves and what the implications of this are for developing a resilient workforce. Authors such as Kruk $e t a l^{8}$ see a strong and committed workforces as a key element of a resilient health system, yet there is little description of what this means for HCWs in low-resourced settings. Within such settings where HCWs are reporting a low QoL and high-risk factors for developing workbased stress, questions need to be asked if they should also shoulder the additional burden of responsibility that a resilient health system will require. If this burden is to be placed on HCWs then further support will be needed to help them manage this.

The training programme devised for the study was well received by both the participants and MoHS. There had been no similar training for HCWs in the country and as a consequence of using the programme in this study further training programmes were instigated by the MoHS. The programme was incorporated into training days for HCWs newly recruited to the MoHS in recognition of the need for more support for HCWs. However, the dynamic situation during the Ebola epidemic will have impacted on the impact of the training programme and the ability of HCWs to provide increased peer support during the epidemic.

\section{CONCLUSION}

A 5-year plan for Sierra Leone to build a more resilient health system that provides routine care as well as being able to withstand any future epidemics is being implemented. Frameworks of resilience cite a committed and strong workforce as being important for developing resilience and health system strengthening but this may be undermined if workers face high levels of stress at work. For the individual high levels of workplace stress may impact personal health and QoL, affecting work performance and personal relationships. It is important therefore that further research is conducted on the best way to support workers in low-income countries and lowresourced working environments to reduce workplace risk factors for stress.

\section{Author affiliations}

${ }^{1}$ School of Nursing and Midwifery, School of Human and Health Sciences, University of Huddersfield, Huddersfield, UK

${ }^{2}$ Centre for Maternal and Newborn Health, Liverpool School of Tropical Medicine, Liverpool, UK

${ }^{3}$ School of Nursing and Midwifery, University of Manchester, Manchester, UK 
Acknowledgements CMNH-LSTM would like to thank the MoHS Sierra Leone and the Ministry of Social Welfare for agreeing for the study to take place and all those healthcare workers who participated in the study.

Contributors SJ and J0 conceptualised the study. SJ, J0, BS, FB and SP conducted the primary research. SJ, SG, SW and NvdB analysed the data. SJ, SG, SW and NvdB, BS, FB, SP wrote the paper.

Funding This study was Funded by WaterAid through VSO.

Competing interests None declared.

Patient consent for publication Not required.

Ethics approval Ethical approval was obtained from the Sierra Leone Ethics and Scientific Review Committee and the Liverpool School of Tropical Medicine Ethics Committee (15.012).

Provenance and peer review Not commissioned; externally peer reviewed.

Data availability statement Data are available upon reasonable request. Data is available upon reasonable request from Dr Barbara Madaj (barbara.madaj@Istmed. ac.uk)

Open access This is an open access article distributed in accordance with the Creative Commons Attribution Non Commercial (CC BY-NC 4.0) license, which permits others to distribute, remix, adapt, build upon this work non-commercially, and license their derivative works on different terms, provided the original work is properly cited, appropriate credit is given, any changes made indicated, and the use is non-commercial. See: http://creativecommons.org/licenses/by-nc/4.0/.

\section{ORCID iDs}

Susan Jones http://orcid.org/0000-0003-0883-4627

Sarah White http://orcid.org/0000-0001-5535-8075

\section{REFERENCES}

1 World Health Organization. World health statistics 2014. Geneva: World Health Organization, 2014. http://apps.who.int/iris/bitstream/ 10665/112738/1/9789240692671_eng.pdf

2 Bolkan HA, Hagander L, von Schreeb J, et al. The surgical workforce and surgical provider productivity in Sierra Leone: a countrywide inventory. World J Surg

3 World Health Organization. Ebola response road map situation report - 27 may 2015. Geneva: World Health organization, 2015. Available: http://apps.who.int/ebola/current-situation/ebola

4 McPake B, Witter S, Ssali S, et al. Ebola in the context of conflict affected states and health systems: case studies of northern Uganda and Sierra Leone. Confl Health 2015;9:23.

5 Jones S, Sam B, Bull F, et al. 'Even when you are afraid, you stay': provision of maternity care during the Ebola virus epidemic: a qualitative study. Midwifery 2017;52:19-26.

6 Lehmann M, Bruenahl CA, Löwe B, et al. Ebola and psychological stress of health care professionals. Emerg Infect Dis 2015;21:913-4

7 Maunder R, Hunter J, Vincent L, et al. The immediate psychological and occupational impact of the 2003 SARS outbreak in a teaching hospital. CMAJ 2003;168:1245-51.

8 van Vegchel $\mathrm{N}$, de Jonge J, Landsbergis PA, et al. Occupational stress in (inter)action: the interplay between job demands and job resources. J Organ Behav 2005;26:535-60.

9 Karasek RA. Job demands, job decision latitude, and mental strain implications for job redesign. Adm Sci Q 1979;24:285-308.

10 Khamisa N, Oldenburg B, Peltzer K, et al. Work related stress, burnout, job satisfaction and general health of nurses. Int $J$ Environ Res Public Health 2015;12:652-66.

11 Portoghese I, Galletta M, Coppola RC, et al. Burnout and workload among health care workers: the Moderating role of job control. Saf Health Work 2014;5:152-7.

12 Van Bogaert P, Adriaenssens J, Dilles T, et al. Impact of role-, joband organizational characteristics on nursing unit managers' work related stress and well-being. J Adv Nurs 2014;70:2622-33.

13 Marsh HW. Construct validity of physical Self-Description questionnaire responses: relations to external criteria. J Sport Exercise Psy 1996;18:111-31.
14 Sull A, Harland N, Moore A. Resilience of health-care workers in the UK; a cross-sectional survey. J Occup Med Toxicol 2015;10:20.

15 McAllister M, McKinnon J. The importance of teaching and learning resilience in the health disciplines: a critical review of the literature. Nurse Educ Today 2009;29:371-9.

16 Fiabane E, Giorgi I, Sguazzin C, et al. Work engagement and occupational stress in nurses and other healthcare workers: the role of organisational and personal factors. J Clin Nurs 2013;22:2614-24.

17 Siegrist J. Adverse health effects of high-effort/low-reward conditions. J Occup Health Psychol 1996;1:27-41.

18 Black BO. Obstetrics in the time of Ebola: challenges and dilemmas in providing lifesaving care during a deadly epidemic. BJOG 2015;122:284-6.

19 Jayasuriya R, Whittaker M, Halim G, et al. Rural health workers and their work environment: the role of inter-personal factors on job satisfaction of nurses in rural Papua New Guinea. BMC Health Serv Res 2012;12:156.

20 Selamu M, Hanlon C, Medhin G, et al. Burnout among primary healthcare workers during implementation of integrated mental healthcare in rural Ethiopia: a cohort study. Hum Resour Health 2019;17:58

21 Newman R. Providing direction on the road to resilience. Behav Health Manag 2003;23:42-3.

22 HSE. Health and safety executive (HSE) work related stress-tools and templates, 2013. Available: http://www.hse.gov.uk/stress/standards/ downloads.htm

23 WHO. World health organisation, 2012. Available: https://www.who. int/mental health/publications/whoqol/en/

24 Banning $\bar{M}$. Approaches to teaching: current opinions and related research. Nurse Educ Today 2005;25:502-8.

25 Hawthorne G, Herrman H, Murphy B. Interpreting the WHOQOLBrèf: preliminary population norms and effect sizes. Soc Indic Res 2006;77:37-59.

26 Skevington SM, Lotfy M, O'Connell KA, et al. The world Health organization's WHOQOL-BREF quality of life assessment: psychometric properties and results of the International field trial. A report from the WHOQOL group. Qual Life Res 2004;13:299-310.

27 Ruotsalainen JH, Verbeek JH, Mariné A, et al. Preventing occupational stress in healthcare workers. Cochrane Database Syst Rev 2015;4:CD002892.

28 Lopes Cardozo B, Gotway Crawford C, Eriksson C, et al. Psychological distress, depression, anxiety, and burnout among international humanitarian aid workers: a longitudinal study. PLOS One 2012;7:e44948.

29 Biggs A, Brough P, Barbour JP. Exposure to extraorganizational stressors: impact on mental health and organizational perceptions for police officers. Int J Stress Manag 2014;21:255-82.

30 Adegoke $A A$, van den Broek N. Skilled birth attendance-lessons learnt. BJOG 2009;116 Suppl 1:33-40.

31 Lavoie-Tremblay M, Trépanier S-G, Fernet C, et al. Testing and extending the triple match principle in the nursing profession: a generational perspective on job demands, job resources and strain at work. J Adv Nurs 2014;70:310-22.

32 Ameh C, Msuya S, Hofman J, et al. Status of emergency obstetric care in six developing countries five years before the mdg targets for maternal and newborn health. PLoS One 2012;7:e49938.

33 Brookes K, Limbert C, Deacy C, et al. Systematic review: workrelated stress and the HSE management standards. Occup Med 2013;63:463-72.

34 Ereno JR, Andrade KM, Miyauchi SI, et al. Encountering and countering work stress: a multivariate analysis of the occupational stress and coping mechanisms of fast food restaurant personnel in the Philippines. Eur Sci J 2014;10:148-58.

35 Toderi S, Balducci C, Edwards JA, et al. Psychometric properties of the UK and Italian versions of the HSE stress indicator tool: a cross cultural investigation. Eur J of Psychol Assess 2013;29:72-9.

36 Windle G, Bennett KM, Noyes J. A methodological review of resilience measurement scales. Health Qual Life Outcomes 2011;9:8.

37 Rubin GJ, Brewin CR, Greenberg N, et al. Psychological and behavioural reactions to the bombings in London on 7 July 2005: cross sectional survey of a representative sample of Londoners. BMJ 2005;331:606.

38 Kruk ME, Myers M, Varpilah ST, et al. What is a resilient health system? lessons from Ebola. Lancet 2015;385:1910-2. 